\title{
A Qualitative Study of Implementing Universal Hepatitis C Screening Among Adults at an Urban Community-Based Health Provider in Delaware
}

\author{
Rini Jose, $\mathrm{MPH}^{1}$, Deborah Kahal, MD, MPH${ }^{2}$, Karla Testa, $\mathrm{MD}^{3}$, Neal D. Goldstein, PhD, MBI \\ 1. Drexel University Dornsife School of Public Health, Department of Epidemiology and \\ Biostatistics
}

2. William J. Holloway Community Program, ChristianaCare; Sidney Kimmel Medical College, Thomas Jefferson University

3. Westside Family Healthcare; Sidney Kimmel Medical College, Thomas Jefferson University

4. Drexel University Dornsife School of Public Health, Department of Epidemiology and Biostatistics

\begin{abstract}
Objectives. We conducted a qualitative study of primary care providers to assess the challenges and opportunities in implementing a universal screening program for Hepatitis C Virus (HCV) at an urban community-based health center serving a largely disadvantaged population. Methods. Qualitative semi-structured interviews of prescribing providers took place pre- and posteducational intervention, at a single federally qualified health center in Wilmington, Delaware, between September 2018 and July 2019. The intervention included a two-day didactic session and shadowing specialist providers. Data captured provider perspectives on universal screening and treatment. The interviews were transcribed verbatim, then grouped into codes, then finally, themes. Results. Emergent themes included hesitancy in managing universal screening programs in the primary care environment, positive attitudes surrounding treatment, fewer HCV cases than expected, and concern with both patient-level barriers and practice-level barriers. Preintervention and post-intervention themes were similar. Conclusions. Implementation programs exploring universal HCV screening in the primary care environment should include educational opportunities that are available to all individuals in the practice, sustained organizational support, and available patient literature targeted to patients with varying health literacy and in languages other than English. In short, universal HCV screening and treatment is feasible in the primary medical environment but requires ongoing support and education for providers to ensure success.
\end{abstract}

\section{Introduction}

Chronic infection with Hepatitis $\mathrm{C}$ virus $(\mathrm{HCV})$ is a widespread bloodborne infectious disease, estimated to affect approximately 2.4 million people in the United States, resulting in approximately $\$ 6.5$ billion dollars in treatment costs. ${ }^{1-3}$ As a result of the opioid epidemic in the United States, increases in injection drug use behaviors have mirrored the increase in reported cases of HCV infection. ${ }^{4}$ Curative treatment is available and effective, but approximately 50 to $75 \%$ of chronically-infected individuals are unaware of their infection status and are therefore left untreated. ${ }^{5}$ If left untreated, HCV can result in cirrhosis, hepatocellular carcinoma, or death. ${ }^{6,7}$ Further, individuals with HCV can transmit this infection to others if they do not take appropriate precautions, for example, by sharing drug paraphernalia. Consequently, as a preventable disease, a primary focus has been on increasing screening and treatment rates. In 
2020, the United States Preventive Services Task Force (USPSTF) recommended a one-time screen for all adults aged 18 to 79 , irrespective of risk factors. ${ }^{8}$ Both the Centers of Disease Control and Prevention (CDC) and the American Association for the Study of Liver Diseases (AASLD) have released similar recommendations. ${ }^{9,10}$ These recommendations will undoubtedly help progress towards HCV elimination; however, many challenges still exist, both on the provider and patient side.

Once the diagnosis of $\mathrm{HCV}$ is made, a key barrier to treatment has been the need for specialty care. Prior to the availability of direct-acting antiviral medications (DAAs), HCV was treated with interferon-based therapies, which were often associated with long treatment duration and poor tolerability. ${ }^{11}$ As a result, specialist care (commonly infectious disease, hepatology, or gastroenterology) was often necessary to successfully manage and treat HCV. With the current state of curative treatment for $\mathrm{HCV}$, however, there is an opportunity to deliver treatment in the primary care setting. Previous research studies have demonstrated that primary care physicians, when properly trained, can achieve high rates of sustained virologic response. ${ }^{12,13}$ In addition, delivering $\mathrm{HCV}$ treatment in the primary care setting may be able to overcome some patient barriers, for example inadequate access to specialty care, that prevented people with $\mathrm{HCV}$ from achieving cure. ${ }^{12,13}$ One study comparing on-site testing and treatment of patients with $\mathrm{HCV}$ to specialist care found that an on-site HCV program resulted in a significantly higher percentage of patients linked to care and cured of their HCV. ${ }^{14}$

The HCV treatment cascade measures patient progression from screening to cure: measuring the number of individuals in a given population that initially test positive for HCV, how many of those individuals are successfully linked-to-care, and of those, how many eventually progress to cure. ${ }^{15}$ Many HCV elimination efforts have incorporated universal (i.e. non-risk factor based) screening for $\mathrm{HCV}$ among all patients aged 18 to 69 years. ${ }^{16}$ There is evidence that universal screening may be an effective approach in reducing HCV infections in the US: one study found that one-time universal screening is more cost-effective than a risk-based screening approach and is widely supported by patients. ${ }^{17}$

A recent mixed-methods study that focused on HCV screening among primary care providers in a large, integrated health system revealed ongoing education for providers, and widespread patient barriers (e.g., financial cost of treatment, competing clinical priorities) as significant barriers to implementation. ${ }^{18}$ In recognition of these findings, and to address gaps in the literature, we sought to better understand barriers to universal HCV screening and treatment among primary care providers in a federally qualified health center (FQHC) which presents unique challenges and opportunities compared to private medical practices. FQHCs are community-based health providers in the U.S. that receive federal funding to provide primary care services. ${ }^{12} \mathrm{FQHCs}$ are typically located in underserved areas and serve historically marginalized patient populations, including uninsured patients, in culturally appropriate and accessible settings. ${ }^{12,13}$ We chose to focus on provider-level experiences and barriers to evaluate the feasibility of shifting screening and treatment to the primary care setting. The goal of this study was to evaluate the implementation of universal screening of HCV into the primary care FQHC environment, measuring the impact this program had among primary care providers in resource-limited, underserved medical practices. 
DOI: $10.32481 / \mathrm{djph} .2021 .07 .006$

\section{Methods}

\section{Overview of the Study and Intervention}

To ascertain the readiness and willingness of providers to screen, treat, and manage patients with $\mathrm{HCV}$, we designed a qualitative study focused on primary healthcare providers at an urban FQHC (Figure 1) between September 2018 and July 2019. Interviews were intended to obtain contextual information on challenges and opportunities towards universal HCV screening. We interviewed physicians and other advanced practice providers (e.g., physician assistants, nurse practitioners) as these groups can have prescribing authority and manage treatment for $\mathrm{HCV}$; for simplicity, we refer to both groups as "prescribers."

Figure 1. Study flow chart depicting the evaluation of a universal Hepatitis $\mathrm{C}$ screening program at an urban community-based health provider.

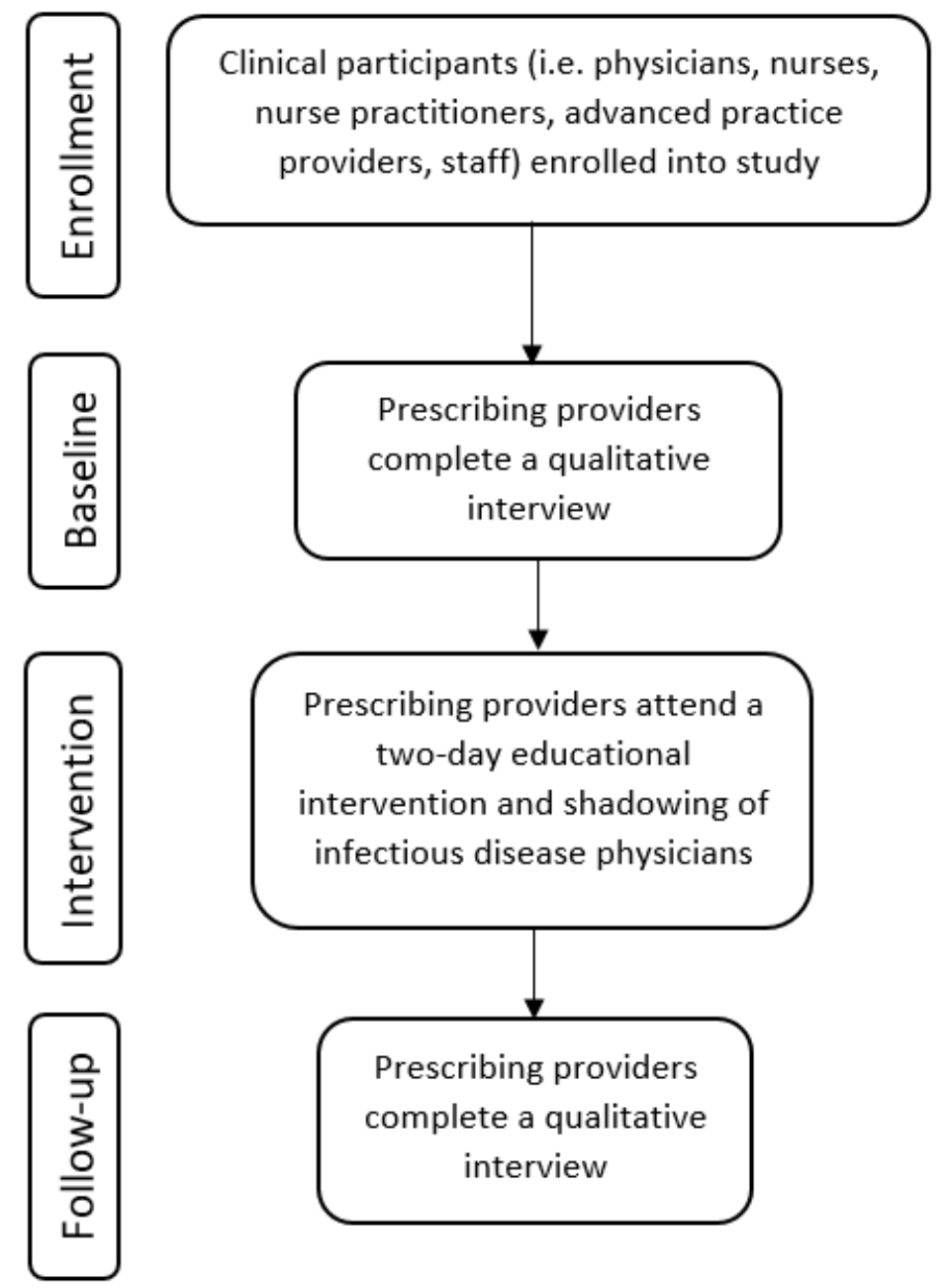

We chose to implement our universal screening program at Westside Family Healthcare (WFH), an urban FQHC in Wilmington, Delaware, United States. In Delaware, there is an estimated statewide HCV sero-prevalence rate of 13,600 individuals. ${ }^{19}$ Wilmington, the largest city in Delaware, is home to more than 70,000 people: more than half of this population is Black or 
African American, and approximately $25 \%$ of this population lives in poverty. ${ }^{20} \mathrm{We}$ focus on the singular site, WFH, for several reasons. First, the catchment includes areas with historically higher rates of $\mathrm{HCV}$, ensuring we serve a community that is disproportionately burdened. Second, the smaller size of the practice made our program feasible to implement. Third, its proximity and connection to the largest healthcare provider in the region (i.e., ChristianaCare) ensured patients would have access to the required resources should treatment and management of complicated cases of HCV not be possible at the primary care site.

The educational intervention consisted of two one-day didactic sessions presented by a multidisciplinary team of infectious disease physicians, clinical pharmacists, social workers, and administrators. Topics included HCV pathophysiology, disease etiology, risk assessment and prevention, targeted risk reduction counseling, diagnosis and treatment, post-treatment monitoring, and referral guidelines. Additionally, several recently cured patients were invited to share their experiences with the group. All prescribers and staff were invited to attend day one, while prescribers attended both days. In addition to the didactic sessions, prescribers shadowed infectious disease physicians to allow for "hands-on" experience in the first few months postintervention. A patient manager was hired to help patients navigate the treatment process and support patients in scheduling appointments and obtaining curative therapies. This study was deemed IRB exempt by ChristianaCare (Newark, DE).

\section{Data Collection and Analysis}

We enrolled providers to participate in semi-structured one-on-one interviews before and after the intervention. These interviews were intended to explore the barriers, opportunities, and experiences of the primary care providers in implementing universal screening at an FQHC. In order to ensure the protection of interviewed prescribers' identities, we do not present demographic data on those interviewed. Interviews were conducted in-person in a private office at WFH in Wilmington, Delaware by one academic epidemiologist and one physician researcher, with doctoral-level degrees.

Participants were first asked to describe their baseline experiences with HCV screening and treatment, including self-identified strengths or weaknesses in managing patients with $\mathrm{HCV}$. Participants were probed to describe the challenges they faced in progressing toward universal screening and treatment of all patients with HCV. Participants were also asked to describe support or additional information they would need to screen and manage HCV independently. On average, each interview lasted 30 minutes and was audio recorded. Participants were asked similar questions during their pre- and post-intervention interviews (see Appendix A). The time frame from pre-intervention interview to post-intervention interview was approximately one year.

Recordings were transcribed verbatim and managed using NVivo version 12 (QSR International, Burlington, MA). Transcripts were coded and analyzed using thematic analysis methods as follows: a priori, structured codes corresponding to the domains in the interview guides were developed. Transcripts were then read to develop a framework of emergent codes reflecting unanticipated themes from the interviews. The coding framework was then applied to the qualitative texts. Discrepancies in coding were discussed with the project team until an appropriate code was agreed upon. In subsequent readings of the text, we grouped codes into themes. Codes were initially developed separately for each interview time point but unifying 
themes were identified across time points. In the final phase of analysis, summative examples of each theme and representative quotes and findings were selected.

\section{Results}

Four prescribers completed the pre-intervention interviews and five completed the postintervention interviews. Table 1 summarizes the major themes from the qualitative interviews that explored the prescribers' thoughts and feelings on universal HCV screening. Themes elucidated in the pre-intervention time period were linked to the post-intervention time period.

Table 1. Major themes from qualitative interviews from provider interviews pre-intervention and post intervention, including exemplary quotes

\begin{tabular}{|c|c|c|c|}
\hline & Theme Description & $\begin{array}{l}\text { Exemplary Quotes, } \\
\text { Pre-Intervention }\end{array}$ & $\begin{array}{l}\text { Exemplary Quotes, } \\
\text { Post-Intervention }\end{array}$ \\
\hline 1 & $\begin{array}{l}\text { Theme 1: Prescribers } \\
\text { describe hesitancy and } \\
\text { lack of comfort in } \\
\text { screening patients for } \\
\text { HCV, limiting measures } \\
\text { of self-assessed } \\
\text { preparedness }\end{array}$ & $\begin{array}{l}\text { “.... a weakness, I think, is } \\
\text { just not knowing the } \\
\text { medications...” } \\
\text { “...how often do I do my } \\
\text { screenings? [...] Like, how } \\
\text { do I - how do I make sure } \\
\text { that I'm doing the right } \\
\text { thing by [my patients]?” }\end{array}$ & $\begin{array}{l}\text { - "So, still not completely } \\
\text { comfortable, because I } \\
\text { haven't had that much } \\
\text { experience..." } \\
\text { - "I have good theoretical } \\
\text { knowledge." }\end{array}$ \\
\hline 2 & $\begin{array}{l}\text { Theme 2: The availability } \\
\text { and effectiveness of } \\
\text { DAAs in this setting } \\
\text { resulted in increased } \\
\text { provider engagement, } \\
\text { positive attitudes, and } \\
\text { optimism in implementing } \\
\text { universal HCV screening } \\
\text { and treatment. }\end{array}$ & $\begin{array}{l}\text { "I'm really happy now, that } \\
\text { there are a lot of treatment } \\
\text { options...I'm really happy } \\
\text { to be }[. . .] \text { a part of this } \\
\text { pilot." }\end{array}$ & $\begin{array}{l}\text { - "It's something we can } \\
\text { actually treat and } \\
\text { cure...that's been } \\
\text { rewarding, in and of itself." }\end{array}$ \\
\hline 3 & $\begin{array}{l}\text { Theme 3: Providers } \\
\text { perceived HCV to be } \\
\text { widespread, but after } \\
\text { implementing universal } \\
\text { HCV screening, providers } \\
\text { felt that patient volume } \\
\text { did not reflect these } \\
\text { beliefs. }\end{array}$ & $\begin{array}{l}\text { • “...everybody should just } \\
\text { get screened.” } \\
\text {. “...if you're sexually active } \\
\text { in this population, I would } \\
\text { screen you for just about } \\
\text { everything.” }\end{array}$ & $\begin{array}{l}\text { - "I guess when it was } \\
\text { presented, we felt like it } \\
\text { was rampant, like [Hepatitis } \\
\text { C] was rampant..." } \\
\text { "I'm not sure that we have } \\
\text { hit the goals that we had set, } \\
\text { where we thought we'd be } \\
\text { as far as the percentage of } \\
\text { patients that we've } \\
\text { screened..." }\end{array}$ \\
\hline 4 & $\begin{array}{l}\text { Theme 4: Providers felt } \\
\text { concerned with patient- } \\
\text { level barriers and } \\
\text { expressed hesitancy in } \\
\text { implementing universal }\end{array}$ & $\begin{array}{l}\text { - "I think just getting to the } \\
\text { appointment is a huge } \\
\text { barrier." } \\
\text { - "[A]t some point, I think } \\
\text { that just the burden of their }\end{array}$ & $\begin{array}{l}\text { "A lot of [patients] have the } \\
\text { misconception that it's a } \\
\text { you know, more of a benign } \\
\text { process, can just hang on to } \\
\text { [Hepatitis C] for a while }\end{array}$ \\
\hline
\end{tabular}




\begin{tabular}{|c|c|c|c|}
\hline & $\begin{array}{l}\text { HCV screening and } \\
\text { treatment in this setting. }\end{array}$ & $\begin{array}{l}\text { healthcare becomes so great } \\
\text { that they're like, why am I } \\
\text { going to go see yet another } \\
\text { specialist and get, you } \\
\text { know, this taken care of? } \\
\text { [...] But we've had a couple } \\
\text { of those types of patients } \\
\text { where it's just there's too } \\
\text { much going on, and } \\
\text { [Hepatitis C] is not my top } \\
\text { priority." }\end{array}$ & $\begin{array}{l}\text { without a whole lot of } \\
\text { serious ramifications. So } \\
\text { that, you know, that } \\
\text { misnomer is something that } \\
\text { we've kind of been } \\
\text { stamping out. So that's a, } \\
\text { that's been at least a mini- } \\
\text { theme, so that's happened } \\
\text { more than once. I think the - } \\
\text { - those same kind of people } \\
\text { are also aware of some of } \\
\text { the difficulties of previous } \\
\text { treatment regimens, } \\
\text { duration and side effects } \\
\text { and all that kind of stuff. So } \\
\text { that kind of comes up in } \\
\text { some of the initial } \\
\text { conversations, too." } \\
\text { "We're trying to educate } \\
\text { patients that it doesn't } \\
\text { matter what your risk } \\
\text { factors are, we just screen } \\
\text { everyone." }\end{array}$ \\
\hline 5 & $\begin{array}{l}\text { Theme 5: Administrative } \\
\text { and practice-level barriers } \\
\text { persisted, limiting the } \\
\text { provider-assessed } \\
\text { effectiveness of universal } \\
\text { screening for HCV in this } \\
\text { setting. }\end{array}$ & $\begin{array}{l}\text {-So we're a primary care } \\
\text { practice, so you bring a } \\
\text { patient in and we're here to } \\
\text { deal with their primary care } \\
\text { issues, but then you have } \\
\text { Hepatitis C or the opioid } \\
\text { dependence, or you know } \\
\text { the patient who is, you } \\
\text { know, depressed. So, in that } \\
\text { ten-minute visit, how do } \\
\text { you treat all of those } \\
\text { things? And that's where } \\
\text { you get a lot of resistance } \\
\text { from primary care because } \\
\text { we would love to do it all } \\
\text { and fix it all but it's like, } \\
\text { how can you do that in this } \\
\text { limited time?" }\end{array}$ & $\begin{array}{l}\text { "“I]n my mind, when I'm } \\
\text { watching kind of those } \\
\text { folks do their thing and take } \\
\text { these histories, my primary } \\
\text { care brain is already saying } \\
\text { I don't have an hour with a } \\
\text { patient to ask all these } \\
\text { questions. So I'm like, how } \\
\text { can I condense what you're } \\
\text { doing in an hour down to } \\
\text { like, you know, five or ten } \\
\text { minutes of conversation } \\
\text { gets the salient pieces out of } \\
\text { it? So that is something that } \\
\text { we will, you know, we will } \\
\text { always need, because we } \\
\text { will never have that hour to } \\
\text { have that conversation." }\end{array}$ \\
\hline
\end{tabular}




\section{Theme 1: Prescribers describe hesitancy and lack of comfort in screening patients for HCV, limiting measures of self-assessed preparedness.}

\section{Pre-intervention Interviews}

All four prescribers interviewed expressed hesitancy in their abilities and readiness in independent screening and treatment of patients with HCV. Although prescribers had different comfort levels with screening and referral of patients, all prescribers expressed a lack of knowledge about the initial patient assessment needed for HCV (e.g., laboratory tests, DAA treatment options). Some prescribers stated they would feel more confident and comfortable in treating this population if these topics were included in the upcoming educational intervention. Prescribers expressed a lack of knowledge about DAAs, including contraindications, and interactions. All prescribers expressed discomfort in communicating with patients who may screen positive, given their lack of knowledge. For example, one provider said, "I need to know how to safely manage those patients." This lack of knowledge and comfort in prescribing limited provider measures of self-assessed preparedness.

\section{Post-intervention Interviews}

Although four of the interviewed prescribers felt that the additional educational sessions improved their comfort levels in assessing $\mathrm{HCV}$ in their patient populations, all five prescribers also felt as though their limited direct experience with screening and treating patients resulted in an ongoing lack of confidence. Many prescribers described the educational sessions as helpful in increasing their comfort levels but felt that their limited experience resulted in hesitancy. Although the educational intervention included shadowing of infectious disease physicians treating patients with $\mathrm{HCV}$, several prescribers expressed discomfort in treating these patients independently. One provider stated that they would benefit from another educational session in the future, describing a "lag between when you learn the information and when you're actually implementing it."

Theme 2: The availability and effectiveness of DAAs in this setting resulted in increased provider engagement, positive attitudes, and optimism in implementing universal HCV screening and treatment.

\section{Pre-intervention Interviews}

Three of the four prescribers interviewed described optimistic and positive attitudes when reflecting on current DAAs. All prescribers described "excitement" in learning more about HCV during the educational intervention, with the hope of being able to treat and cure HCV in their patients. For example, one prescriber felt DAAs were promising, stating:

"As a practitioner, as a clinician, it's really awesome to see that change, and really think about how HCV can be something in our lifetime that we could $[\ldots]$ cure, and almost eradicate..."

\section{Post-intervention Interviews}

Three of the five prescribers described their attitude towards HCV treatment as positive, resulting in widespread benefits from the intervention and pilot program. One prescriber said: 
"I think it's definitely been a really good learning experience for me personally and the rest of the staff here and hopefully $[\ldots]$ our patients have benefitted from that."

Prescribers described the experience as "rewarding," because HCV is curable, stating, "you can't say in medicine that we can actually cure many things." The curative ability of DAAs was a large factor in engaging prescribers in universal screening and treatment. Provider reflections on curative therapy for $\mathrm{HCV}$ also resulted in many prescribers feeling positively about universal screening.

\section{Theme 3: Prescribers perceived HCV to be widespread, but after implementing universal HCV screening, prescribers felt that patient volume did not reflect these beliefs.}

\section{Pre-intervention Interviews}

When asked about their previous experiences in screening "high-risk" patients for HCV, all prescribers interviewed discussed sexually transmitted infections (STIs). Several prescribers also expressed a willingness to screen for HCV outside of STIs. As one provider stated:

“...a lot of our patients are lower socioeconomic status, increased risk $[\ldots]$ should be screened as well $[\ldots]$ everybody should just get screened."

One provider described their screening practices as "liberal," explaining they would screen irrespective of perceived risk status. Three of the four prescribers discussed the need for increased screening and treatment in their patient populations, describing HCV as a highly prevalent illness. These prescribers described the true prevalence of $\mathrm{HCV}$ [in their patient population] as being largely unknown, which is likely why they felt that an intervention that involved increased screening and treatment was necessary. None of the prescribers expressed concern in adapting their practice to incorporate universal HCV screening. Indeed, many prescribers felt that universal HCV screening was a logical next step in screening practices.

\section{Post-intervention Interviews}

Four of the five prescribers interviewed discussed a disconnect between their expectations of $\mathrm{HCV}$ prevalence and their subsequent experiences after instituting universal screening, describing a lack of patient volume and fewer positive cases than anticipated. Despite this, many prescribers felt that universal screening efforts were necessary and should be continued. For example, one provider stated:

"I think that [increased patient volume] will come, I think it just shows that you really need time to create this groundwork...I think that treatment piece, once we actually get started and [see] more patients [...] I think it [will] be great for us in the community..."

Several prescribers described sexual risk and HCV risk as linked, but also described universal HCV screening as necessary to identify new cases. It is important to note that although sexual risk does play a small role in $\mathrm{HCV}$ transmission, shared drug-injection paraphernalia is the primary mode of HCV transmission and has contributed substantially to HCV prevalence in the United States. ${ }^{21}$ Prescribers also felt that HCV was still prevalent in the community, even though 
several prescribers described their patient volumes as not reflecting this belief. Many prescribers also concluded that continued screening of all patients might readily identify new cases of HCV and with time, may reflect the perceived high prevalence of $\mathrm{HCV}$.

\section{Theme 4: Prescribers felt concerned with patient-level barriers and expressed frustration in implementing universal HCV screening and treatment in this setting.}

\section{Pre-intervention Interviews}

Three of four prescribers discussed patient barriers as a major concern with implementing universal HCV screening. Prescribers listed several perceived patient barriers, including reliance on public transportation, changeable/unreliable patient contact information, unstable housing, lower health literacy, lack of finances, and insurance concerns. For example, one provider explained their frustration addressing patient barriers:

"We tried to call, their phone doesn't work anymore, they changed addresses, and so it's more of a shell game of trying to figure out where they are..."

For many of the prescribers, getting patients invested in curing their HCV felt like a barrier in and of itself: prescribers frequently described asymptomatic patients that have lived with their $\mathrm{HCV}$ for long periods of time as being less willing to begin treatment. Many prescribers expressed a concern that patients would not feel motivated to treat their HCV because of patients' competing priorities from a personal perspective (e.g., unstable housing, drug use) or from a health perspective (e.g., comorbidities). Prescribers felt that conversations with patients would be challenging because asymptomatic patients might feel that treating and curing their HCV could wait or was not a priority for them.

\section{Post-intervention Interviews}

Prescribers described a challenging patient population that contended with unstable housing, little to no health insurance, and financial challenges that prevented them from seeking treatment for health issues. For example, one provider described their patient population as having, "enough issues with transportation and affordability and things like that." Prescribers also felt that encouraging patients to invest in HCV treatment was a persistent barrier. Prescribers felt that many patients did not prioritize curing their HCV. One provider identified a "mini-theme," among their patients: some patients with asymptomatic HCV felt their infection was benign and therefore, not necessary to be treated. All prescribers expressed the same concern. Some had an easier time negotiating these conversations, as one provider described two different patient groups they have encountered: patients who describe HCV treatment as "...not high on their priority list, whether it's their medical issues, or whether it's the other social issues that they're dealing with. And then those patients who have been like, oh, yeah, like I, I definitely want to get treated."

Prescribers observed that encouraging patient engagement in treatment was the most frequent barrier to screening and treating patients for HCV. However, some prescribers felt this patient hesitancy and poor patient investment in treatment came from a lack of patient information. Several prescribers explained that increasing health literacy among patients may increase patient HCV screening and treatment. A few prescribers also described challenges in effective communication with patients who speak English as a second language. As one provider stated: 
"You don't know what their background is, telling the patient something that you're telling, you don't know that that message is getting through."

Several prescribers noted that patient education (i.e., various media and incorporating diverse reading-levels) including native-speaker translations in commonly spoken languages (e.g., Spanish at this FQHC) may be effective in encouraging patients to seek HCV screening and treatment.

\section{Theme 5: Administrative and practice-level barriers persisted, limiting the provider-assessed effectiveness of universal screening for HCV in this setting.}

\section{Pre-intervention Interviews}

Prescribers discussed staff and nurse education as an anticipated practice-level barrier in instituting universal HCV screening. One provider described the impact of educating the supportive staff as, "huge," and that education would "help change the culture here." In addition, many of the prescribers interviewed also discussed concerns with having enough time with patients. One provider described resistance from primary care prescribers to institute universal screening primarily due to concerns about time with patients and time for staff education. Prior to the educational intervention, prescribers were concerned about educating all staff who interact with patients. Many prescribers felt that because staff (e.g., administrative staff, medical assistants) are sometimes the first individuals to interact with a patient in the office, they should be included in the conversation surrounding HCV screening and treatment.

\section{Post-intervention Interviews}

After the educational intervention, many prescribers still felt that time was an issue. Some prescribers felt that this could be improved with increased staff with focused tasks, including additional nursing staff that are in contact with patients and are able to answer questions regarding HCV. Prescribers also voiced concerns with managing the electronic health record system, explaining that ordering testing and extracting patient data felt cumbersome. Several prescribers also described a sense of being overwhelmed with tasks which one provider described as "pilot fatigue." As this provider explained:

"In an organization like ours, where we always have a million things going on at once [...] people are just used to making changes on such a regular basis."

Lack of support from staff, prescribers, and the organization at a higher-level were frequently discussed during interviews. Although overall, prescribers felt positively about HCV screening and treatment, they also expressed concern that inclusion of universal HCV screening into primary care practices could result in a sense of feeling overwhelmed or fatigued. Likely as a result of this concern, prescribers suggested that increased investment in time, personnel, or training at the organizational level may encourage sustained adoption of HCV screening and treatment by primary care prescribers. 
DOI: $10.32481 / \mathrm{djph} .2021 .07 .006$

\section{Discussion}

The results of this study suggest that while universal adult HCV screening in the primary care setting is feasible, and that universal adult HCV screening is an important step toward HCV eradication in the United States and elsewhere, barriers persist, especially in an FQHC environment. ${ }^{22}$ Our results echo previous findings that primary care prescribers want to increase HCV screening and treatment but feel hesitant because of their subject-specific knowledge level. ${ }^{23-25}$

Themes that emerged during the qualitative interviews suggest that although primary care prescribers feel positively about universal HCV screening and treatment, organizational and patient investment are integral in ensuring an effective program. Notably, themes identified during qualitative interviews were consistent across time points. There are several reasons for this finding: firstly, this could be a result of the time between interviews. Perhaps, additional time is necessary to observe actionable differences between pre- and post-intervention interviews. Secondly, the intervention was designed to improve the knowledge of prescribers, consisting of two one-day didactic sessions and a hands-on shadowing of practice. This intervention did not address many of the barriers that prescribers mentioned in the interview (e.g., increased nursing staff, patient buy-in). Therefore, themes were relatively consistent across time points as prescribers reiterated additional opportunities identified through their practices, which they believed would strengthen the program.

As previous research suggests, prescriber investment and support is the key to a program's success. ${ }^{23,26}$ In our study, prescribers described "pilot fatigue," in which resources are invested in new programs as they initialize but emphasis fades over time. This issue, as well as additional findings from our study, support the need for interventions that include training of and support for staff and physicians, despite competing priorities and limitations on time, a commonly cited barrier in implementation of programs in healthcare settings. ${ }^{27}$ Prescriber interviews included recommendations to increase organizational investment and support in programs past their initial implementation, increase staff numbers to ensure staff do not feel overwhelmed by program expectations, and encourage ongoing education for prescribers and staff. To improve our implementation of universal screening the study team conducted monthly meetings for 6 months post-implementation. This pilot program also included onboarding a patient navigator to address some of these time and task constraints, although prescribers still felt that more support was necessary. Further, this pilot program also included increased patient signage in patient areas (e.g., waiting rooms) in both English and Spanish, describing HCV infection and treatment. Despite this, prescribers still felt that patients needed additional information and educational items. The most effect strategy identified was educating the medical assistant staff, as they were the first point of engagement with the patient to offer HCV screening. Following this pilot study, WFH has since expanded universal screening to other FQHC sites in the State.

Data from this study suggest that universal HCV screening and treatment may be possible in the primary care setting, however these programs need sustained organizational support and resources. Although prescribers noted several anticipated and experienced barriers in universal screening, for many, the experience of treating and curing HCV outweighed these limitations. A coordinated effort from all levels of the healthcare paradigm is necessary to ensure successful implementation of any clinical program. ${ }^{28}$ 
In contrast with previous efforts to introduce universal HCV screening in the primary care setting, results from the present study benefited from widespread availability of DAAs for HCV treatment. Similar studies conducted within the FQHC context found that while patients may be successfully linked to care, the number of patients who begin treatment is low. ${ }^{29}$ Insurance payers have made it increasingly difficult for patients to get prior authorization or to afford $\mathrm{HCV}$ treatment, resulting in low cure rates. ${ }^{30}$ As many prescribers described in their qualitative interviews, increased investment in time, personnel, and training at the organizational level may be critical in sustained and successful adoption of HCV screening and treatment programs.

Our study has important strengths and limitations. In focusing on an urban FQHC, we were also able to target an underserved population and a resource-limited provider population. A limitation of this research was the relatively small number of prescribers available for our qualitative interviews: all eligible providers were interviewed. Also, our findings may only reflect experiences in an urban community-based health center serving mostly marginalized groups, and not necessarily generalize to all adult outpatient medical settings.

\section{Public Health Implications}

The results of this study demonstrate feasibility of expansion of universal HCV screening in primary care settings, particularly amongst a resource-limited practice situated within an underserved patient population. Our findings highlight the opportunities and challenges towards universal screening for $\mathrm{HCV}$ in the primary care environment and may be useful for other practices considering the implementation of a similar program. To ensure implementation of a successful program, organizations must ensure continued, sustained support and education for prescribers pre- and post-implementation. ${ }^{23,26,28}$

Conflict of Interest: The authors declare that they have no conflict of interest.

Funding: Research reported in this publication was supported by an award from the Christiana Care Harrington Value Institute Community Partnership (to DK, NDG).

Correspondence: Rini Jose, rj499@drexel.edu

\section{REFERENCES}

1. Aceijas, C., \& Rhodes, T. (2007, October). Global estimates of prevalence of HCV infection among injecting drug users. The International Journal on Drug Policy, 18(5), 352-358. PubMed https://doi.org/10.1016/j.drugpo.2007.04.004

2. Hofmeister, M. G., Rosenthal, E. M., Barker, L. K., Rosenberg, E. S., Barranco, M. A., Hall, E. W., . . Ryerson, A. B. (2019, March). Estimating prevalence of hepatitis C virus infection in the United States, 2013-2016. Hepatology (Baltimore, Md.), 69(3), 1020-1031. PubMed https://doi.org/10.1002/hep.30297

3. Razavi, H., Elkhoury, A. C., Elbasha, E., Estes, C., Pasini, K., Poynard, T., \& Kumar, R. (2013, June). Chronic hepatitis C virus (HCV) disease burden and cost in the United States. Hepatology (Baltimore, Md.), 57(6), 2164-2170. PubMed https://doi.org/10.1002/hep.26218

4. Zibbell, J. E., Asher, A. K., Patel, R. C., Kupronis, B., Iqbal, K., Ward, J. W., \& Holtzman, D. (2018, February). Increases in acute hepatitis $\mathrm{C}$ virus infection related to a growing opioid epidemic and associated injection drug use, United States, 2004 to 2014. American 
Journal of Public Health, 108(2), 175-181. PubMed

https://doi.org/10.2105/AJPH.2017.304132

5. Denniston, M. M., Klevens, R. M., McQuillan, G. M., \& Jiles, R. B. (2012, June).

Awareness of infection, knowledge of hepatitis $\mathrm{C}$, and medical follow-up among individuals testing positive for hepatitis C: National Health and Nutrition Examination Survey 20012008. Hepatology (Baltimore, Md.), 55(6), 1652-1661. PubMed https://doi.org/10.1002/hep.25556

6. McHutchison, J. G., Bacon, B. R., \& Owens, G. S. (2007, December). Making it happen: Managed care considerations in vanquishing hepatitis C. The American Journal of Managed Care, 13(12, Suppl 12), S327-S336. PubMed

7. Seeff, L. B., \& Hoofnagle, J. H. (2003, February). Appendix: The National Institutes of Health Consensus Development Conference Management of Hepatitis C 2002. Clinics in Liver Disease, 7(1), 261-287. PubMed https://doi.org/10.1016/S1089-3261(02)00078-8

8. Owens, D. K., Davidson, K. W., Krist, A. H., Barry, M. J., Cabana, M., Caughey, A. B., . . Wong, J. B., \& the US Preventive Services Task Force. (2020, March 10). Screening for hepatitis $\mathrm{C}$ virus infection in adolescents and adults: US Preventive Services Task Force recommendation statement. JAMA, 323(10), 970-975. PubMed https://doi.org/10.1001/jama.2020.1123

9. Schillie, S., Wester, C., Osborne, M., Wesolowski, L., \& Ryerson, A. B. (2020, April 10). CDC recommendations for hepatitis C screening among adults - United States, 2020. MMWR Recomm Rep, 69(2), 1-17. PubMed https://doi.org/10.15585/mmwr.rr6902a1

10. Ghany, M. G., Marks, K. M., Morgan, T. R., Wyles, D. L., Aronsohn, A. I., Bhattacharya, D., ... Gordon, S. C. (2020). Hepatitis C guidance 2019 update: AASLD-IDSA recommendations for testing, managing, and treating hepatitis $\mathrm{C}$ virus infection. Hepatology (Baltimore, Md.), 71(2), 686-721. PubMed https://doi.org/10.1002/hep.31060

11. Manns, M. P., Wedemeyer, H., \& Cornberg, M. (2006, September). Treating viral hepatitis C: Efficacy, side effects, and complications. Gut, 55(9), 1350-1359. PubMed https://doi.org/10.1136/gut.2005.076646

12. Arora, S., Thornton, K., Murata, G., Deming, P., Kalishman, S., Dion, D., .. . Qualls, C. (2011, June 9). Outcomes of treatment for hepatitis C virus infection by primary care providers. The New England Journal of Medicine, 364(23), 2199-2207. PubMed https://doi.org/10.1056/NEJMoa1009370

13. Kattakuzhy, S., Gross, C., Emmanuel, B., Teferi, G., Jenkins, V., Silk, R., . . Kottilil, S., \& the and the ASCEND Providers. (2017, September 5). Expansion of treatment for hepatitis $\mathrm{C}$ virus infection by task shifting to community-based nonspecialist providers: A nonrandomized clinical trial. Annals of Internal Medicine, 167(5), 311-318. PubMed https://doi.org/10.7326/M17-0118

14. Coyle, C., Moorman, A. C., Bartholomew, T., Klein, G., Kwakwa, H., Mehta, S. H., \& Holtzman, D. (2019). The Hepatitis C Virus Care Continuum: Linkage to Hepatitis C Virus Care and Treatment Among Patients at an Urban Health Network, Philadelphia, PA. Hepatology. 
15. Trooskin, S. B., Poceta, J., Towey, C. M., Yolken, A., Rose, J. S., Luqman, N. L., . . Nunn, A. S. (2015, July). Results from a geographically focused, community-based HCV screening, linkage-to-care and patient navigation program. Journal of General Internal Medicine, 30(7), 950-957. PubMed https://doi.org/10.1007/s11606-015-3209-6

16. Saab, S., Le, L., Saggi, S., Sundaram, V., \& Tong, M. J. (2018, June). Toward the elimination of hepatitis C in the United States. Hepatology (Baltimore, Md.), 67(6), 24492459. PubMed https://doi.org/10.1002/hep.29685

17. Coffin, P. O., Stevens, A. M., Scott, J. D., Stekler, J. D., \& Golden, M. R. (2011, June 6). Patient acceptance of universal screening for hepatitis $\mathrm{C}$ virus infection. BMC Infectious Diseases, 11(1), 160. PubMed https://doi.org/10.1186/1471-2334-11-160

18. Higashi, R. T., Jain, M. K., Quirk, L., Rich, N. E., Waljee, A. K., Turner, B. J., . . Singal, A. G. (2020). Patient and Provider-Level Barriers to Hepatitis C Screening and Linkage to Care: A Mixed-Methods Evaluation. Journal of viral hepatitis.

19. Rosenberg, E. S., Hall, E. W., Sullivan, P. S., Sanchez, T. H., Workowski, K. A., Ward, J. W., \& Holtzman, D. (2017, June 1). Estimation of state-level prevalence of hepatitis C virus infection, US states and District of Columbia, 2010. Clin Infect Dis, 64(11), 1573-1581. PubMed https://doi.org/10.1093/cid/cix202

20. U. S. Census Bureau. Census QuickFacts. Retrieved from https://www.census.gov/quickfacts/wilmingtoncitydelaware

21. Trickey, A., Fraser, H., Lim, A. G., Peacock, A., Colledge, S., Walker, J. G., . . Vickerman, P. (2019, June). The contribution of injection drug use to hepatitis $C$ virus transmission globally, regionally, and at country level: A modelling study. The Lancet. Gastroenterology \& Hepatology, 4(6), 435-444. PubMed https://doi.org/10.1016/S2468-1253(19)30085-8

22. Shiffman, M. L. (2016, January). Universal screening for chronic hepatitis C virus. Liver Int, 36(Suppl 1), 62-66. PubMed https://doi.org/10.1111/liv.13012

23. Grebely, J., Oser, M., Taylor, L. E., \& Dore, G. J. (2013, March). Breaking down the barriers to hepatitis $\mathrm{C}$ virus (HCV) treatment among individuals with $\mathrm{HCV} / \mathrm{HIV}$ coinfection: Action required at the system, provider, and patient levels. The Journal of Infectious Diseases, 207(Suppl 1), S19-S25. PubMed https://doi.org/10.1093/infdis/jis928

24. Litwin, A. H., Kunins, H. V., Berg, K. M., Federman, A. D., Heavner, K. K., Gourevitch, M. N., \& Arnsten, J. H. (2007, July). Hepatitis C management by addiction medicine physicians: Results from a national survey. Journal of Substance Abuse Treatment, 33(1), 99-105. PubMed https://doi.org/10.1016/j.jsat.2006.12.001

25. Lambert, S. M., Page, A. N., Wittmann, J., Hayllar, J. S., Ferndale, C. W., Bain, T. M., \& Macdonald, G. A. (2011). General practitioner attitudes to prescribing hepatitis $\mathrm{C}$ antiviral therapy in a community setting. Australian Journal of Primary Health, 17(3), 282-287. PubMed https://doi.org/10.1071/PY10069

26. Ockene, J. K., \& Zapka, J. G. (2000, August). Provider education to promote implementation of clinical practice guidelines. Chest, 118(2, Suppl), 33S-39S. PubMed https://doi.org/10.1378/chest.118.2_suppl.33S 
27. Rahm, A. K., Boggs, J. M., Martin, C., Price, D. W., Beck, A., Backer, T. E., \& Dearing, J. W. (2015). Facilitators and barriers to implementing Screening, Brief Intervention, and Referral to Treatment (SBIRT) in primary care in integrated health care settings. Substance abuse, 36(3), 281-288. PubMed https://doi.org/10.1080/08897077.2014.951140

28. Chaudoir, S. R., Dugan, A. G., \& Barr, C. H. (2013, February 17). Measuring factors affecting implementation of health innovations: A systematic review of structural, organizational, provider, patient, and innovation level measures. Implement Sci, 8(1), 22. PubMed https://doi.org/10.1186/1748-5908-8-22

29. Coyle, C., Kwakwa, H., \& Viner, K. (2016, May-June). Integrating routine HCV testing in primary care: Lessons learned from five federally qualified health centers in Philadelphia, Pennsylvania, 2012-2014. Public Health Rep, 131(2,2_Suppl), 65-73. PubMed https://doi.org/10.1177/00333549161310S211

30. Coffin, P. O., \& Reynolds, A. (2014, July 3). Ending hepatitis C in the United States: The role of screening. Hepatic Medicine : Evidence and Research, 6, 79-87. PubMed https://doi.org/10.2147/HMER.S40940 
DOI: $10.32481 /$ djph.2021.07.006

\section{Appendix A}

HCV Qualitative Interview Guide: Pre-intervention.

1. Tell me about your experience, if any, with managing hepatitis $C$ ? This can include experiences dating back to your medical training or graduate studies.

2. Describe your comfort level with taking care of patient with hepatitis $\mathrm{C}$, including any strengths or weaknesses.

3. What do you think you will need to learn to be able to manage hepatitis $\mathrm{C}$ for your primary care patients?

Can prompt them to include any specific topics including:

- Screening and evaluating for HCV

- Staging and screening labs/imaging

- Who to treat

- When to refer

4. What are you hoping to learn and/or feel more comfortable with following the HCV training that will be provided as part of this collaboration?

5. What are some ways in which your clinic can help support your ability to take care of your primary care patients with hepatitis $\mathrm{C}$ ?

6. Is there anything we did not touch on that you would like to share surrounding hepatitis C?

HCV Qualitative Interview Guide: Post-intervention.

1. Tell me about your experience, if any, with managing hepatitis $\mathrm{C}$ this past year [since we provided HCV education and started working together on the grant]

2. Describe your current comfort level with taking care of patient with hepatitis $\mathrm{C}$, including any strengths or weaknesses.

Can prompt and specifically inquire about changes in comfort level over the past year

3 . Is there anything additional you feel is needed to be able to manage hepatitis $\mathrm{C}$ for your primary care patients?

Can prompt them to include any specific topics including:

- More education, (Screening and evaluating for HCV, Staging and screening labs/imaging, who to treat, A

- More personnel, resources, etc.

- Describe, be specific

If not getting much response, can also try this question:

What are some ways in which your clinic can further support your ability to screen adults for HCV and take care of those patients infected with HCV? 
DOI: $10.32481 / \mathrm{djph} .2021 .07 .006$

4. Did you attend the HCV education sessions that included formal training ( $2 \frac{1}{2}$ days of education) plus shadowing last year?

\section{If NO, skip to Q6}

If YES, continue

5. Thinking back to the provided HCV education (includes $2 \frac{1}{2}$ days of formal training modules plus shadowing), do you have feedback or comments you would like to share on the content or delivery of that education? We will be conducting the same session at a second site in the near future.

Can prompt them if needed:

- Strengths

-Weaknesses

- Areas that needed more focus/less focus

- Areas that you found to be very beneficial and/or not beneficial

6. Is there anything we did not touch on that you would like to share surrounding $\mathrm{HCV}$ or your experience collaborating with us to expand access to HCV care?

Copyright (c) 2021 Delaware Academy of Medicine / Delaware Public Health Association.

This is an Open Access article distributed under the terms of the Creative Commons Attribution NonCommercial License (https://creativecommons.org/licenses/by-nc-nd/4.0/) which permits unrestricted noncommercial use, distribution, and reproduction in any medium, provided the original work is properly cited. 